www.mdpi.com/journal/applsci

Article

\title{
Magnetic Amphiphilic Composites Applied for the Treatment of Biodiesel Wastewaters
}

\author{
Bruno R. S. Lemos ${ }^{1}$, Ana Paula C. Teixeira ${ }^{1}$, José D. Ardisson ${ }^{2}$, Waldemar A. A. Macedo ${ }^{2}$, \\ Luis E. Fernandez-Outon ${ }^{2}$, Camila C. Amorim ${ }^{3}$, Flávia C. C. Moura ${ }^{1}$ and Rochel M. Lago ${ }^{1}$ ** \\ 1 Departamento de Química, Universidade Federal de Minas Gerais, Belo Horizonte, MG, \\ 31270-901, Brazil; E-Mails: brunoroch@ufmg.br (B.R.S.L.); anapct@ufmg.br (A.P.C.T.); \\ flaviamoura@ufmg.br (F.C.C.M.) \\ 2 Laboratório de Física Aplicada, Centro de Desenvolvimento da Tecnologia Nuclear - \\ CDTN/CNEN, Belo Horizonte, MG, 31270-901, Brazil; E-Mails: jdr@cdtn.br (J.D.A.); \\ wmacedo@cdtn.br (W.A.A.M.); lefo@cdtn.br (L.E.F.-O.) \\ 3 Departamento de Engenharia Sanitária e Ambiental, Universidade Federal de Minas Gerais, Belo \\ Horizonte, MG, 31270-901, Brazil; E-Mail: camila@desa.ufmg.br (C.C.A.) \\ * Author to whom correspondence should be addressed; E-Mail: rochel@ufmg.br; \\ Tel: +55-31-3409-5775; Fax: +55-31-3409-5700.
}

Received: 20 April 2012; in revised form: 4 May 2012 / Accepted: 18 May 2012 /

Published: 29 May 2012

\begin{abstract}
In this work, new magnetic amphiphilic composites were prepared by chemical vapor deposition with ethanol on the surface of hydrophilic natural chrysotile matrix containing Fe catalyst. XRD, Raman, Mössbauer and SEM analyses suggest the formation of a complex nanostructured material composed of hydrophobic carbon nanotubes/nanofibers grown on the hydrophilic surface of the MgSi fiber mineral and the presence of Fe metallic nanoparticles coated by carbon. These nanostructured particles show amphiphilic properties and interact very well with both oil and aqueous phases. When added to emulsions the amphiphilic particles locate on the oil/water interface and, under a magnetic field, the oil droplets collapsed leading to the separation of the aqueous and oil phases. Preliminary work showed excellent results on the use of these particles to break wastewater emulsions in the biodiesel process.
\end{abstract}

Keywords: magnetic amphiphilic systems; chrysotile; biodiesel wastewater; breaking emulsions process 


\section{Introduction}

Amphiphilic composites can be potentially applied in several important processes such as adsorption, emulsification and demulsification of oil-water systems [1-3] present in different industrial and environmental areas such as pesticides [4], essential oils and flavors [5], pharmaceutical [6], laundries and effluents treatment [7].

We have recently reported a new amphiphilic magnetic nanostructured composite, based on carbon nanotubes and nanofibers supported on hydrophilic materials, e.g., Al and Si oxides, containing carbon coated magnetic Fe particles [8-13]. These composites showed remarkable capacity to break emulsions under magnetic field. Microscopic investigation showed that, due to the amphiphilic properties the composite particles interact with oil droplets in emulsions and under a magnetic field, the droplets are dragged and by collision collapse lead to a phase separation.

In this work, we produced novel magnetic amphiphilic composites by combining two different types of fibers, i.e., the inorganic chrysotile and carbon fibers. The chrysotile fibers are impregnated with Fe catalyst to grow carbon nanotubes and nanofibers by CVD (Chemical Vapour Deposition) [10]. The amphiphilic character of these composites is due to the hydrophobic nature of carbon nanotubes and nanofibers combined with the hydrophilic surface of the $\mathrm{Mg}$ silicate present in the chrysotile fibers. Chrysotile is natural lamellar phyllosilicate mineral with a fibrous structure [14], with nano to micrometric dimensions [15].The ideal chemical formula of chrysotile is $\mathrm{Mg}_{3} \mathrm{Si}_{2} \mathrm{O}_{5}(\mathrm{OH})_{4}$ with tetrahedral layer of $\mathrm{SiO}_{4}{ }^{2-}$ and a octahedral layer of $\mathrm{Mg}(\mathrm{OH})_{2}$. These composites were used to separate oil contamination in emulsified wastewaters from biodiesel production. In general, for each liter of biodiesel approximately three liters of emulsified wastewater are produced and must be treated [16]. These emulsified wastewaters (oil/water) generated during the process of purification and washing of biodiesel are characterized by high concentration of suspended solids and high levels of organic matter, i.e., chemical oxygen demand (COD), oils and greases. Therefore, there is a considerable interest to develop efficient processes to separate oil from emulsified biodiesel wastewaters.

\section{Experimental Section}

\subsection{Synthesis and Characterization of Magnetic Amphiphilic Composites}

Crysotile fibers were obtained from SAMA (Brazil). Initially, the mineral was impregnated with iron nitrate ( 1 and $25 \mathrm{wt} \%$ of iron), dissolved in distilled water followed by slow evaporation and then dried at $80{ }^{\circ} \mathrm{C}$ for $12 \mathrm{~h}$. Carbon nanostructures were synthesized by CVD method. For the synthesis of amphiphilic magnetic composites were used $500 \mathrm{mg}$ of the impregnated material. This synthesis was carried out in the tubular quartz reactor ethanol under $\mathrm{N}_{2}$ flow entrained by $\left(100 \mathrm{~mL} \cdot \mathrm{min}^{-1}\right)$ containing $6.5 \%$ ethanol vapor introduced by a saturator of ethanol at room temperature. In a horizontal furnace the temperature was raised from room temperature to $800{ }^{\circ} \mathrm{C}$ at $10^{\circ} \mathrm{C} \mathrm{min}{ }^{-1}$ for $1 \mathrm{~h}$. The samples were named $\mathrm{Fe} 1 \%$ and $\mathrm{Fe} 25 \%$ for chrysolite impregnated by 1 and $25 \mathrm{wt} \%$ iron after CVD process. The samples were characterized by powder XRD (Rigaku DIMAX Cu radiation), Mössbauer spectroscopy (on a conventional spectrometer in transmission geometry with a constant acceleration, using a ${ }^{57} \mathrm{Co}$ source in a $\mathrm{Rh}$ matrix. The isomer shifts of the spectra are referred to the centroid of an $\alpha-\mathrm{Fe}$ foil reference spectrum at room temperature), TG/DTG (Shimatzu, under air with a heating rate 
of $10^{\circ} \mathrm{C} \cdot \mathrm{min}^{-1}$ up to $900{ }^{\circ} \mathrm{C}$ ), Raman spectroscopy (SENTERRA at $\lambda=514.5 \mathrm{~nm}$ ), SEM (FEI Quanta 200 microscope, operated at a voltage of $30 \mathrm{kV}$ under high vacuum) and magnetization measurements (using a LakeShore 7404 vibrating sample magnetometer with noise base of $1 \times 10^{-6} \mathrm{emu}$ ). Magnetic hysteresis loops were measured at room temperature using a vibrating sample magnetometer, with time constant of $100 \mathrm{~ms}$, averaging time of $1 \mathrm{~s}$ per point, measurement time of $100 \mathrm{~s}$ and a sweep rate of 1,385 Oe/s. Temperatures were stable to better than $1 \mathrm{~K} /$ hour. The linear contribution to the measurement due to the sample holder was removed from the data presented. Values of the saturation magnetization are referred to the maximum applied field of $14 \mathrm{kOe}$.

The surface area values were obtained in an Autosorb 1 Quantachrome equipment using 22 cycles $\mathrm{N}_{2}$ adsorption/desorption. Total carbon elemental analyses were made using a PERKIN ELMER CHN-PE-2400.

\subsection{Emulsion Studies}

The biodiesel wastewater was collected in a Brazilian biodiesel refinery that uses soybeans through the alkaline transesterificacion process, and used without any pretreatment.

In these studies, $100 \mathrm{mg}$ of the prepared materials or AC (activated carbon from coconut shell, Sulfal), used as a blank or comparison, were added to $6 \mathrm{~mL}$ of emulsified biodiesel wastewater in a test tube (1 cm diameter and $10 \mathrm{~cm}$ length), and the resulting suspension was mixed in a vortex for $1 \mathrm{~min}$. Thereafter, a magnet was approached to the wall of the test tube to attract the magnetic particles leading to emulsion breaking. The absorbance was monitoring by measures of electronic absorption UV-vis (UV 2550 Shimadzu spectrometer). The correlation between absorbance and turbidity systems was done by measures of dilutes wastewater solutions (Turbidimeter HACH 2100 AN). The emulsion breaking process was also analyzed by optical microscopy Cole Parmer Instrument, 41500-50.

\section{Results and Discussion}

\subsection{Synthesis and Characterization}

The fibrous magnetic amphiphilic nanostructured composites were produced by impregnation of chrysotile with iron nitrate ( 1 and $25 \mathrm{wt} \%$ of iron, named hereon as $\mathrm{Fe} 1 \%$ and $\mathrm{Fe} 25 \%$ ) followed by a CVD process to grow carbon nanostructures using ethanol as carbon source according to the Figure 1.

During the CVD the temperature is increased from 30 up to $800^{\circ} \mathrm{C}$. The iron precursor impregnated on the chrysotile fibers is initially thermally decomposed to $\mathrm{Fe}_{2} \mathrm{O}_{3}$. In the presence of ethanol and as the temperature increases, $\mathrm{Fe}_{2} \mathrm{O}_{3}$ is then gradually reduced to form $\mathrm{Fe}_{3} \mathrm{O}_{4}, \mathrm{FeO}$ and finally $\mathrm{Fe}^{0}$ with the main volatile products $\mathrm{CO}_{\mathrm{x}}$ and $\mathrm{H}_{2} \mathrm{O}$.

$$
\mathrm{Fe}_{2} \mathrm{O}_{3} \rightarrow \mathrm{Fe}_{3} \mathrm{O}_{4} \rightarrow \mathrm{FeO} \rightarrow \mathrm{Fe}^{0}
$$


Figure 1. Preparation of magnetic amphiphilic nanoparticles based on Chrysotile obtained by CVD with ethanol.

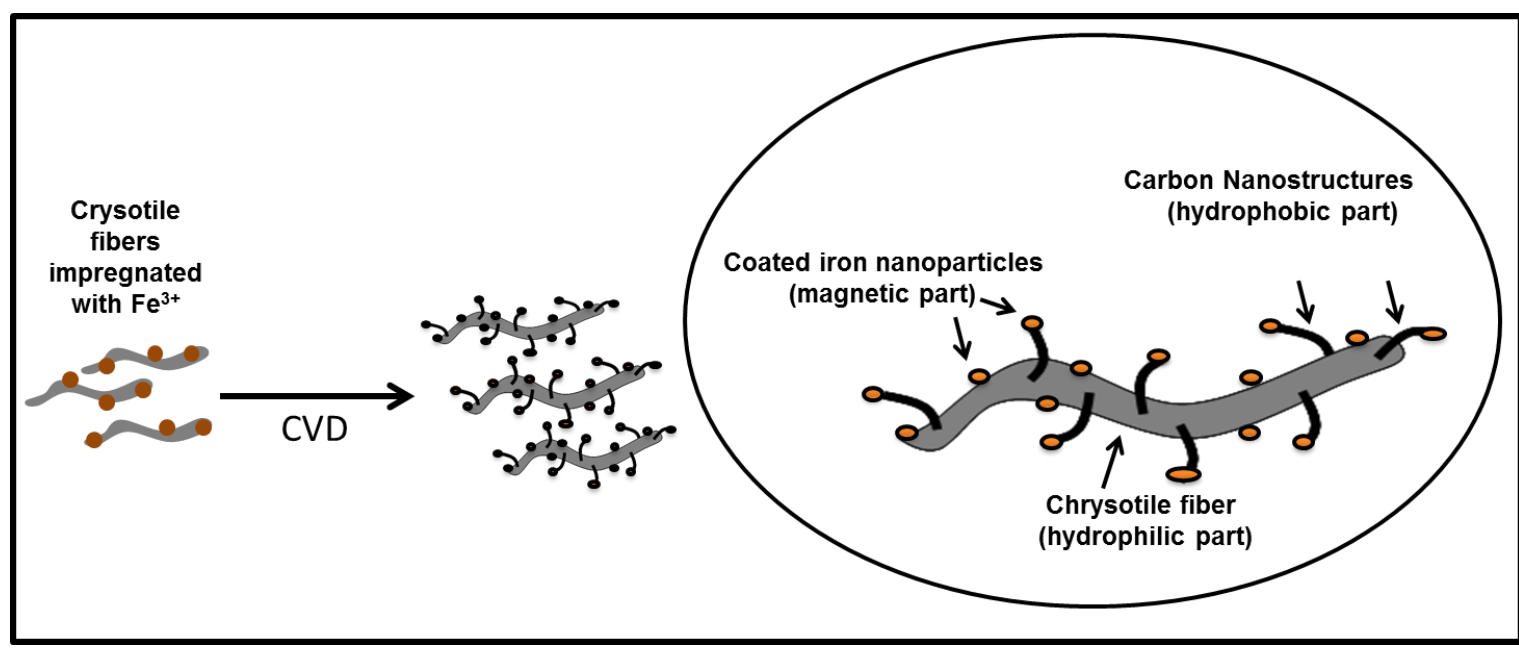

Figure 2. SEM images of chrysotile and magnetic amphiphilic nanoparticles (Fe1\% and $\mathrm{Fe} 25 \%$ ).

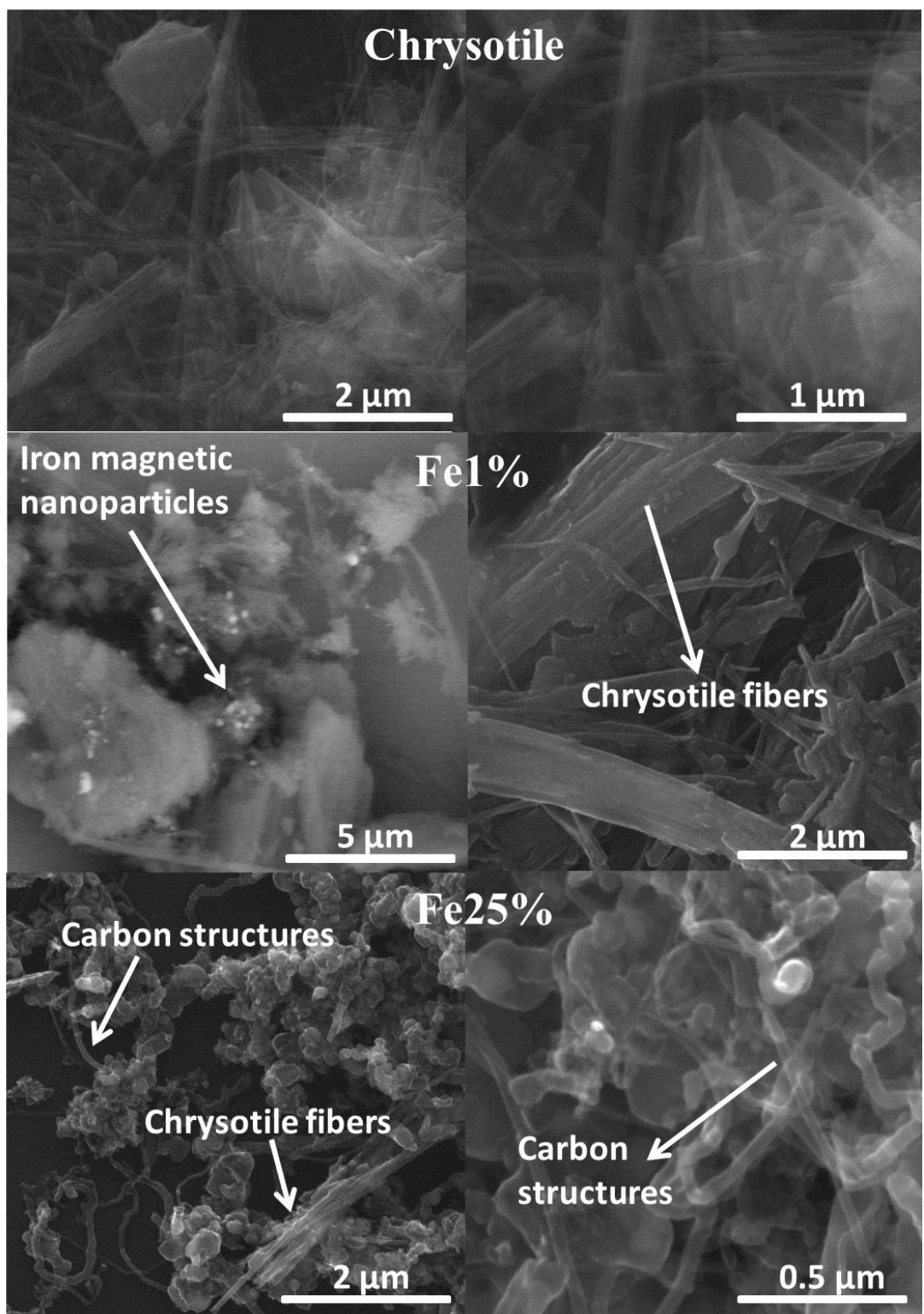


Figure 2 shows SEM images for the pure chrysotile and the prepared magnetic nanostructured composites. Fe1\% shows the presence of chrysotile with agglomerated spherical particles likely related to metallic iron particles on the mineral surface. It was not possible to clearly visualize carbon structures formed in this sample due to the low carbon deposition. In fact, according to the elemental analysis the produced carbon yield was approximately 3\%. Fe25\% also shows the chrysotile fibers with agglomerated metallic iron particles. SEM images suggest that most of these particles are in the range 100-500 $\mathrm{nm}$. Moreover, several bundles of carbon nanostructures, e.g., nanofibers and nanotubes, can be observed over the chrysotile fiber surface.

The materials have also been characterized by thermal analysis. Figure 3 shows the TG/DTG for the materials $\mathrm{Fe} 1 \%$ and $\mathrm{Fe} 25 \%$.

Figure 3. TG/DTG curves of magnetic amphiphilic nanoparticles Fe1\% and Fe25\%.

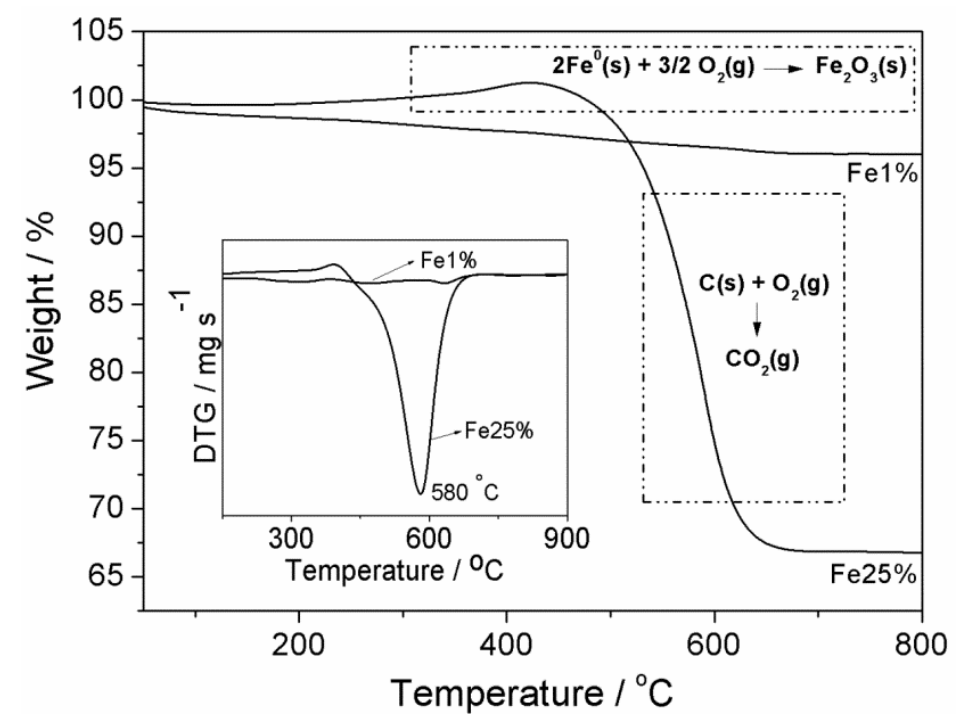

TG curve in air of the material $\mathrm{Fe} 1 \%$ showed a weight loss of $3 \%$ up to $800{ }^{\circ} \mathrm{C}$ related to carbon oxidation (Equation (2)). On the other hand, the TG curve for the material Fe25\% showed initially a weight gain up to $400{ }^{\circ} \mathrm{C}$ associated to the iron oxidation (Equation (3)). After $400{ }^{\circ} \mathrm{C}$ up to $650{ }^{\circ} \mathrm{C}$ the TG curve of the material Fe25\% showed a weight loss of $35 \%$ that is related to carbon oxidation according to Equation (3).

$$
\begin{aligned}
& \mathrm{C}(\mathrm{g})+\mathrm{O}_{2}(\mathrm{~g}) \rightarrow \mathrm{CO}_{2}(\mathrm{~g}) \\
& 2 \mathrm{Fe}^{0}(\mathrm{~s})+3 / 2 \mathrm{O}_{2}(\mathrm{~g}) \rightarrow \mathrm{Fe}_{2} \mathrm{O}_{3}(\mathrm{~s})
\end{aligned}
$$

It is interesting to note that carbon oxidation occurs at a maximum of velocity at $580{ }^{\circ} \mathrm{C}$ and in a very narrow temperature range, i.e., between 500 and $650{ }^{\circ} \mathrm{C}$, which is typical for oxidation of carbon nanotubes and nanofibers structures [17]. This content of carbon present in the material $\mathrm{Fe} 25 \%$ is very close to the one obtained by carbon elemental analyses of $40 \%$.

Raman spectra of the magnetic amphiphilic composites Fe1\% and Fe25\% (Figure 4) showed a band at approximately $1,350 \mathrm{~cm}^{-1}$ (D band) which is related to defects in the carbon structures such as graphite or amorphous carbon [18]. The other band in region of $1,500-1,600 \mathrm{~cm}^{-1}$ ( $\mathrm{G}$ Band) is associated with the vibrations of $\mathrm{C}-\mathrm{C}$ bonds in tangential directions observed graphitic materials. The $\mathrm{G}$ band can indicate the presence of multiwall nanotubes, nanofibers, nano-onion or graphitic layers 
that grow on metallic particles [19]. Therefore both materials led to the formation of carbon structures. No RBM modes, typical of small diameter nanotubes [19], were observed for the materials Fe1\% or $\mathrm{Fe} 25 \%$. The ratio of the intensities of $\mathrm{G}$ and $\mathrm{D}$ bands $\left(\mathrm{I}_{\mathrm{G}} / \mathrm{I}_{\mathrm{D}}\right)$ is $c a .1$ for Fe1\% and lower than 1 for Fe25\%, which indicates that higher concentrations of iron leads to the formation of carbon structures being more defective.

Figure 4. Raman spectra of magnetic amphiphilic nanoparticles $\mathrm{Fe} 1 \%$ and $\mathrm{Fe} 25 \%$.

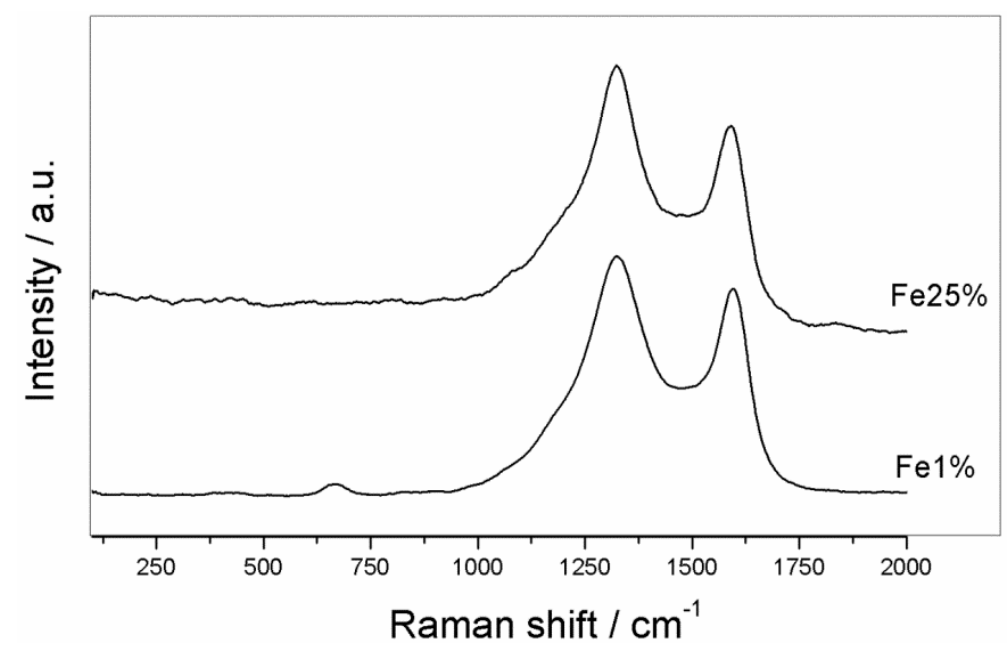

The magnetic composites were characterized by X-ray diffraction (Figure 5). The XRD patterns (Figure 5) of the chrysotile impregnated with iron after the CVD process showed typical reflections of forsterite phase, $\mathrm{Mg}_{2} \mathrm{SiO}_{4}$, which is a magnesium silicate resulting from heat treatment of chrysotile [20]. The XRD patterns also showed the presence of typical reflections of carbide phase, $\mathrm{Fe}_{3} \mathrm{C}$, and iron metal. The graphitic carbon phase is only observed for the material with $25 \% \mathrm{wt}$ iron $(\mathrm{Fe} 25 \%)$.

Figure 5. XRD patterns for Cris, $\mathrm{Fe} 1 \%$ and $\mathrm{Fe} 25 \%$.

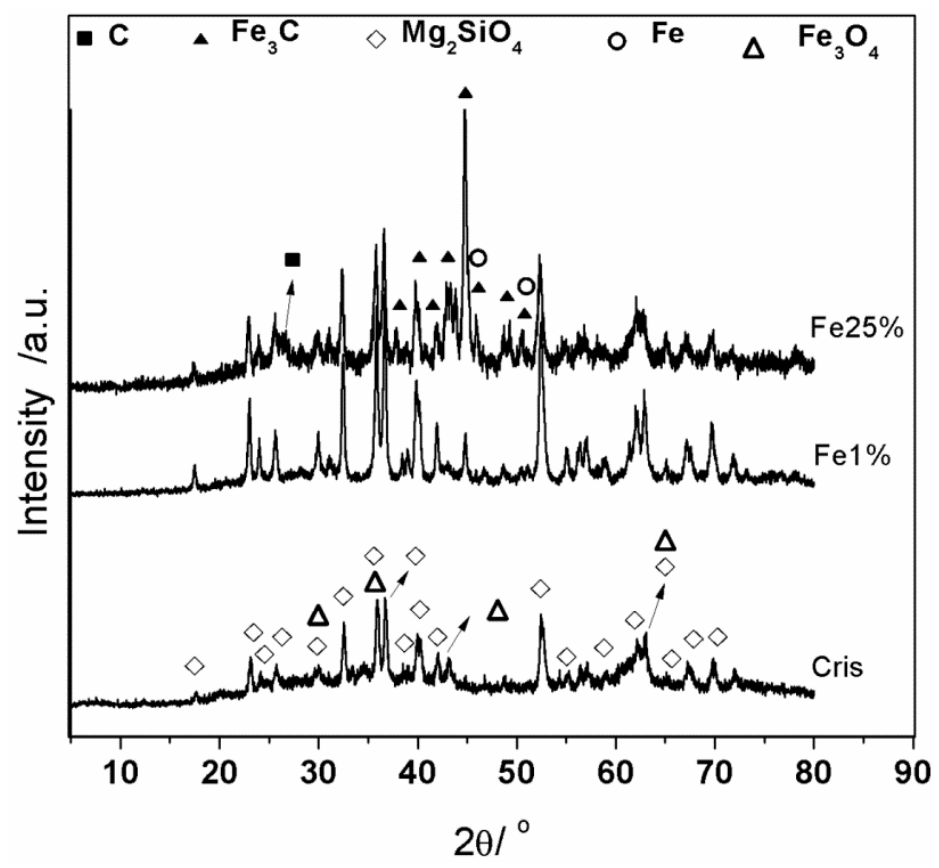


The iron phases present in the magnetic amphiphilic material based on chrysotile were confirmed by Mössbauer spectroscopy (Figure 6). Figure 7 shows a plot of distribution of the iron phases for $\mathrm{Fe} 1 \%$ and $\mathrm{Fe} 25 \%$.

Figure 6. Mössbauer spectra at room temperature of magnetic amphiphilic nanoparticles $\mathrm{Fe} 1 \%$ and $\mathrm{Fe} 25 \%$.



Figure 7. Mössbauer iron phases distribution of $\mathrm{Fe} 1 \%$ and $\mathrm{Fe} 25 \%$.

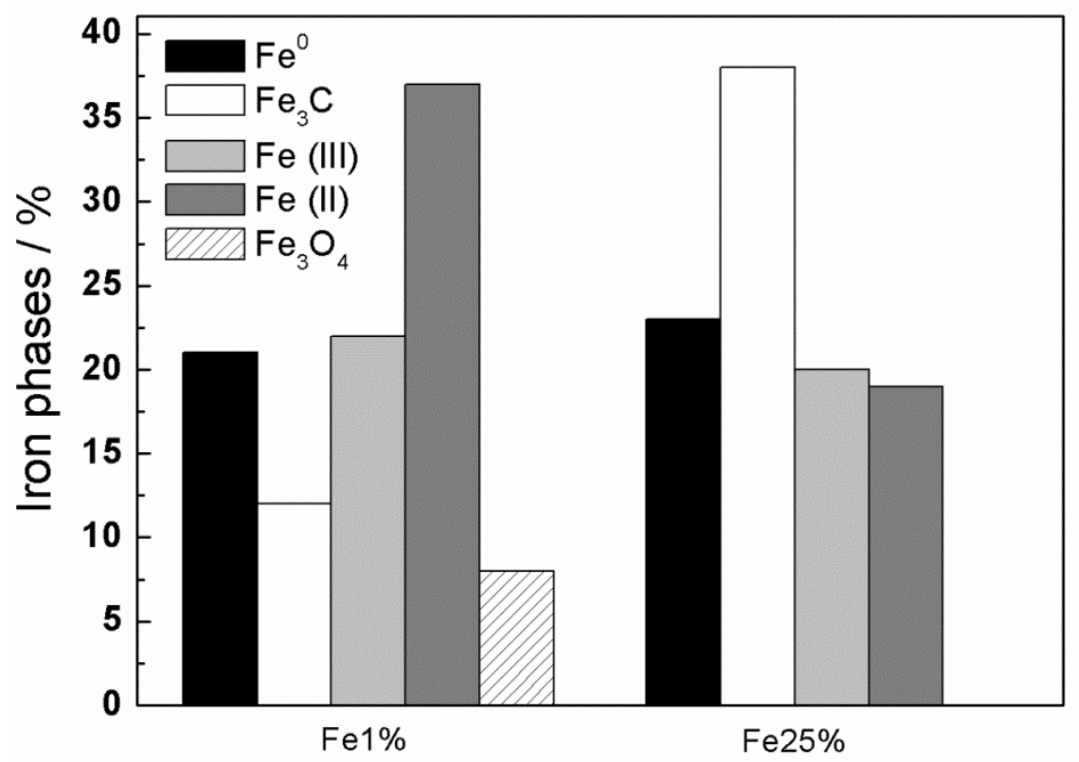

Mössbauer spectrum of amphiphilic material Fe1\% (Figure 6) showed the presence of a sextet related of metallic iron $\left(\delta=0 \mathrm{~mm} \cdot \mathrm{s}^{-1}, \Delta=0 \mathrm{~mm} \cdot \mathrm{s}^{-1}, \mathrm{~B}_{\mathrm{HF}}=33 \mathrm{~T}\right)$ with relative area of $21 \%$, and signals related to the reduced iron oxide, magnetite $\mathrm{Fe}_{3} \mathrm{O}_{4},\left(\delta=0.66\right.$ and $0.23 \mathrm{~mm} \cdot \mathrm{s}^{-1}, \Delta=0.02 \mathrm{~mm} \cdot \mathrm{s}^{-1}$, $\mathrm{B}_{\mathrm{HF}}=46.2$ and $\left.48.2 \mathrm{~T}\right)$ with relative area of $8 \%$ and finally iron carbide $\left(\delta=0.16 \mathrm{~mm} \cdot \mathrm{s}^{-1}\right.$, $\Delta=-0.02 \mathrm{~mm} \cdot \mathrm{s}^{-1}, \mathrm{~B}_{\mathrm{HF}}=20.6 \mathrm{~T}$ ) with relative area of $12 \%$, formed during the CVD process. $\mathrm{Fe} 1 \%$ 
also shows the presence of $\mathrm{Fe}^{3+}$ and $\mathrm{Fe}^{2+}$ in two different phases. The $\mathrm{Fe}^{3+}\left(\delta=0.37, \Delta=0.84 \mathrm{~mm} \cdot \mathrm{s}^{-1}\right.$ and relative area $22 \%$ ) can be associated to the replacement of $\mathrm{Si}^{4+}$ in the structure of chrysotile and hence forsterite. The presence of $\mathrm{Fe}^{2+},\left(\delta=1.14\right.$ and $0.89 \mathrm{~mm} \cdot \mathrm{s}^{-1}, \Delta=2.90$ and $\left.0.89 \mathrm{~mm} \cdot \mathrm{s}^{-1}\right)$ with relative area of $37 \%$ can be associated with ferrous ions that replaced the magnesium in some positions of forsterite $[21,22]$. In these phase, $\mathrm{Mg}^{2+}$ and $\mathrm{Fe}^{2+}$ can consequently take two octahedral sites in the crystal lattice structure of these mineral.

For the Mössbauer spectrum amphiphilic material Fe25\% also it is possible to observe the presence of metallic iron with relative area of $23 \%\left(\delta=0 \mathrm{~mm} \cdot \mathrm{s}^{-1}, \Delta=0 \mathrm{~mm} \cdot \mathrm{s}^{-1}, \mathrm{~B}_{\mathrm{HF}}=33 \mathrm{~T}\right)$ and the absence of the magnetite phase. The magnetite is likely reduced by $\mathrm{H}_{2}$ and carbon formed in large amounts in the sample Fe25\% during the CVD process according to Equation (1). The CVD process led to the formation of large amounts $(38 \%)$ of iron carbide $\left(\delta=0.16 \mathrm{~mm} \cdot \mathrm{s}^{-1}, \Delta=-0.02 \mathrm{~mm} \cdot \mathrm{s}^{-1}, \mathrm{~B}_{\mathrm{HF}}=20.6 \mathrm{~T}\right)$.

An important feature of the composites $\mathrm{Fe} 1 \%$ and $\mathrm{Fe} 25 \%$ is the strong magnetic behavior probably related to the presence of $\mathrm{Fe}^{0}, \mathrm{Fe}_{3} \mathrm{O}_{4}$, and iron carbide $\left(\mathrm{Fe}_{3} \mathrm{C}\right)$ [23]. The presence of these magnetic phases is very interesting for the applications of these materials. In fact, the chrysotile impregnated with iron after CVD process has high values of magnetization. Figure 8 and Table 1 show the hysteresis loops and the main magnetic parameters for the samples Fe1\% and Fe25\%. It can be observed that the saturation magnetization $\left(\mathrm{M}_{\mathrm{s}}\right)$ is larger for the sample with more Fe content, in agreement with the results obtained from Mössbauer spectra, where it shows that sample Fe $25 \%$ has a larger contribution of alpha-Fe and $\mathrm{Fe}$ carbide. The low remanence values result in a small squareness ratio(S), being 8 and $10 \%$ for samples $\mathrm{Fe} 1 \%$ and Fe25\%, respectively. A value of S less than $25 \%$ indicates that a certain population of the particles is in a superparamagnetic state at the temperature of measurement. These correlate with the fact that the samples do not saturate at $14 \mathrm{kOe}$. These results also agree with the Mössbauer data (Figure 7) which show large contribution of superparamagnetic phases for both samples.

Figure 8. Magnetization curves of $\mathrm{Fe} 1 \%$ and $\mathrm{Fe} 25 \%$, after CVD process.

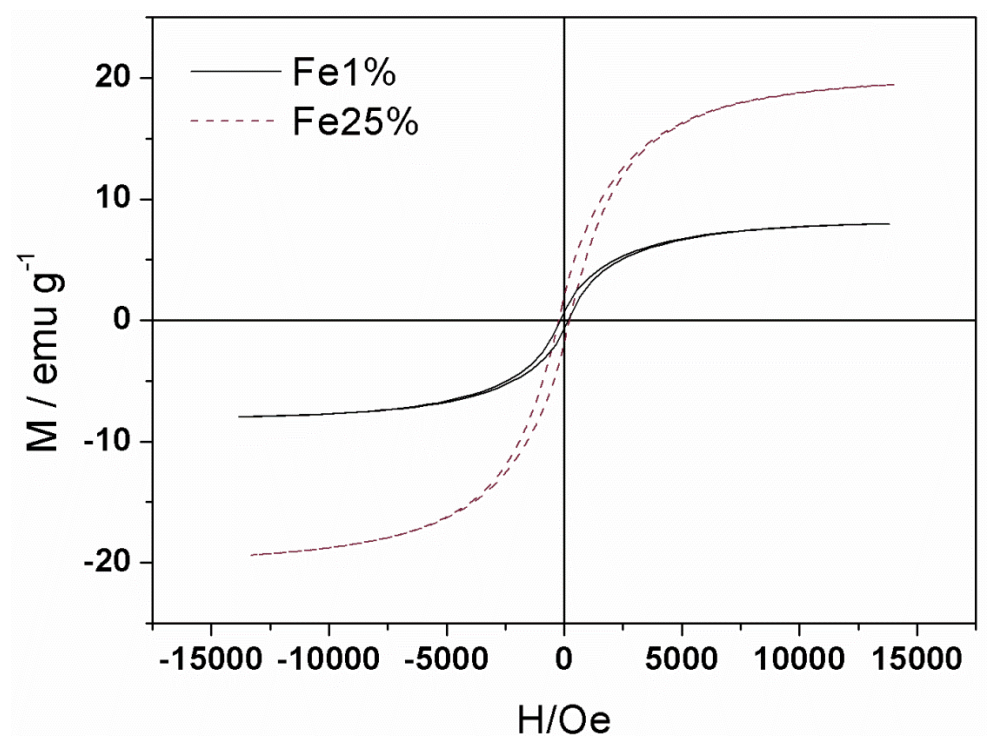


Table 1. Relevant data obtained by magnetization analysis of $\mathrm{Fe} 1 \%$ and $\mathrm{Fe} 25 \%$

\begin{tabular}{ccccc}
\hline Sample & $\mathbf{M}_{\mathbf{S}}(\mathbf{e m u} / \mathbf{g})$ & $\mathbf{M}_{\mathbf{R}}(\mathbf{e m u} / \mathbf{g})$ & $\mathbf{S}=\mathbf{M}_{\mathbf{R}} / \mathbf{M}_{\mathbf{S}}$ & $\mathbf{H}_{\mathbf{C}}(\mathbf{O e})$ \\
\hline $\mathrm{Fe} 1 \%$ & 7.97 & 0.63 & 0.08 & 158 \\
\hline $\mathrm{Fe} 25 \%$ & 19.46 & 1.91 & 0.10 & 226 \\
\hline
\end{tabular}

\subsection{Emulsion Studies}

Figure 9 shows the emulsion breaking process, promoted by the amphiphilic materials. Figure 9(a) shows a sample of a real biodiesel effluent as a stable emulsion with a microscopic view (Figure 9(b)). When the magnetic amphiphilic composite was introduced (Figure 9(c)) the nanostructured particles locate at the interface biodiese1/water, around the dispersed oil drops (Figure 9(d)). In this stage (even before magnetic separation) it can already be noted an oil phase separation by the presence of a thin black layer at the top of the test tube. The black color of this layer is related to the presence of small amounts of the composited retained by the oil phase. After applying a magnet, the material is attracted and dragging the drops together, breaking the emulsion. It was observed a decrease of turbidity after magnetic separation process (Figure 9(e)).

Figure 9. (a) Real biodiesel wastewater emulsified. (b) Optical microscopy images of oil drops into real biodiesel wastewater. (c) Real biodiesel wastewater with amphiphilic material. (d) Oil drops covered by amphiphilic material. (e) Real biodiesel wastewater after magnetic separation process.
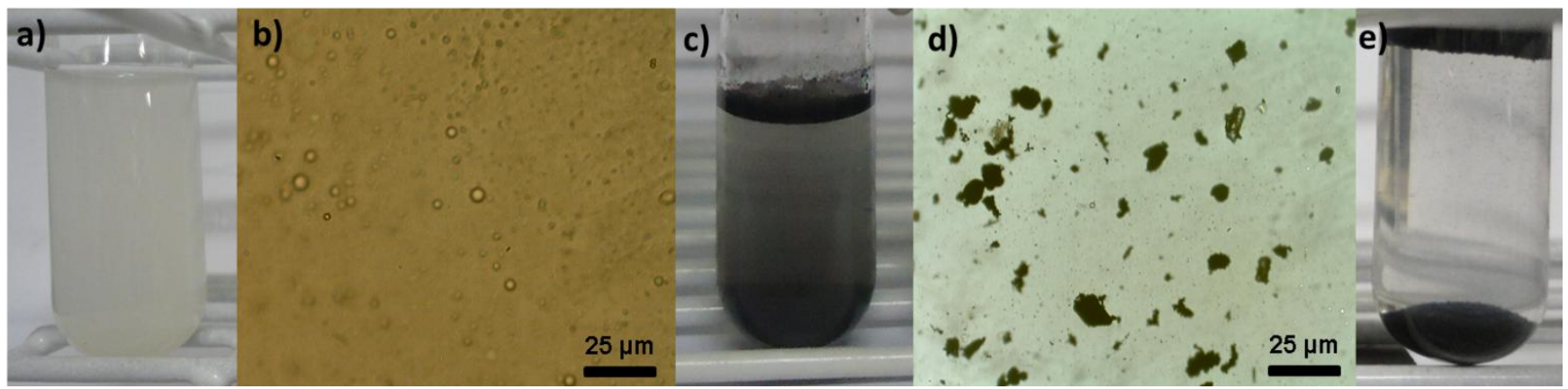

The efficiency of biodiesel wastewater emulsion separation was monitored by turbidimetric measurements. Table 2 shows the surface area and turbidity reduction of the emulsified biodiesel wastewater comparing different materials, i.e., Fe1\%, Fe25\%, chrysotile fibers before and after treatment up to $800{ }^{\circ} \mathrm{C}$ and high surface area activated carbon (AC) used as comparison.

It was observed that the materials were efficient in the turbidity removal of the biodiesel effluent reaching ca. $97 \%$ of turbidity removal. This result suggests that the destabilization/breaking of emulsion promoted by amphiphilic material is more efficient than the adsorption process using activated carbon which removed only $77 \%$ of turbidity (Table 2). These results clearly show that magnetic amphiphilic materials are much more efficient in the process of emulsion breaking and the separation of the material. 
Table 2. Surface area of the materials used and turbidity removal of biodiesel wastewater upon contact and separation with different materials.

\begin{tabular}{cccc}
\hline Materials & Surface Area $\mathbf{~ m}^{\mathbf{2}} \cdot \mathbf{g}^{\mathbf{- 1}}$ & Turbidity Reduction/\% & Process \\
\hline Fe1\% & 7 & 86 & $\begin{array}{c}\text { Mixture of composites and simple } \\
\text { magnetic separation }\end{array}$ \\
\hline Fe25\% & 51 & 97 & $\begin{array}{c}\text { Mixture of composites and simple } \\
\text { magnetic separation }\end{array}$ \\
\hline $\begin{array}{c}\text { Chrysotile } \\
\text { Fibers }\end{array}$ & 22 & 38 & $\begin{array}{c}\text { Mixture of chrysotile and filtration } \\
\text { Fibers/800 }{ }^{\circ} \mathrm{C}\end{array}$ \\
\hline AC & 7 & 2 & $\begin{array}{c}\text { Mixture of thermally treated } \\
\text { chrysotile and filtration }\end{array}$ \\
\hline
\end{tabular}

\section{Conclusions}

Magnetic amphiphilic materials based on chrysotile matrix, carbon nanostructures and magnetic iron particles can be obtained by CVD method using ethanol as carbon source. This amphiphilic material can interact simultaneously with oil and aqueous phases and can be efficiently used in emulsion breaking processes. The composite obtained by impregnating of $25 \%$ wt Fe on chrysotile, led to $40 \%$ of carbon deposition via CVD with ethanol. This material proved to be efficient for breaking stable emulsion in real biodiesel wastewater. Tests have shown that the amphiphilic material has been able to remove up to $96 \%$ of the turbidity of the effluent. Furthermore this composite can be easily removed from the medium by simple magnetic separation process.

\section{Acknowledgments}

The authors are grateful to CNPq, FAPEMIG, PRPq-UFMG and CAPES for the financial support. Especially grateful to Fapemig TEC APQ APQ-03944-10.

\section{References}

1. Kraft, D.J.; Luigjes, B.; de Folter, J.W.J.; Philipse, A.P.; Kegel, W.K. Evolution of Equilibrium Pickering Emulsions-A Matter of Time Scales. J. Phys. Chem. B 2010, 114, 12257-12263.

2. Wen, Y.; Cheng, H.; Lu, L.J.; Liu, J.; Feng, Y.; Guan, W.; Zhou, Q.; Huang, X.F. Analysis of biological demulsification process of water-in-oil emulsion by Alcaligenes sp S-XJ-1. Bioresource Technol. 2010, 101, 8315-8322.

3. Alvarez, G.; Poteau, S.; Argillier, J.F.; Langevin, D.; Salager, J.L. Heavy oil-water interfacial properties and emulsion stability: Influence of dilution. Energ. Fuels 2009, 23, 294-299.

4. Basheer, C.; Suresh, V.; Renu, R.; Lee, H.K. Development and application of polymer-coated hollow fiber membrane microextraction to the determination of organochlorine pesticides in water. J. Chromatogr. A 2004, 1033, 213-220. 
5. Lee, J.; Jha, A.K.; Bose, A.; Tripathi, A. Imaging new transient nanostructures using a microfluidic chip integrated with a controlled environment vitrification system for cryogenic transmission electron microscopy. Langmuir 2008, 24, 12738-12741.

6. Ma, X.W.; Zhao, Y.L.; Liang, X.J. Theranostic nanoparticles engineered for clinic and pharmaceutics. Accounts Chem. Res. 2011, 44, 1114-1122.

7. Hebrant, M.; Tecilla, P.; Scrimin, P.; Tondre, C. Copper(II) complexation by hydrophobic singleand double-alkyl chain ligands solubilized in ammonium surfactant vesicles. Langmuir 1997, 13, 5539-5543.

8. Oliveira, A.A.S.; Teixeira, I.F.; Ribeiro, L.P.; Tristao, J.C.; Dias, A.; Lago, R.M. Magnetic amphiphilic composites based on carbon nanotubes and nanofibers grown on an inorganic matrix: Effect on water-oil interfaces. J. Brazil. Chem. Soc. 2010, 21, 2184-2188.

9. Oliveira, A.A.S.; Tristao, J.C.; Ardisson, J.D.; Dias, A.; Lago, R.M. Production of nanostructured magnetic composites based on $\mathrm{Fe}(0)$ nuclei coated with carbon nanofibers and nanotubes from red mud waste and ethanol. Appl. Catal. B-Environ. 2011, 105, 163-170.

10. Teixeira, A.P.C.; Purceno, A.D.; Barrosa, A.S.; Lemos, B.R.S.; Ardisson, J.D.; Macedo, W.A.A.; Nassor, E.C.O.; Amorim, C.C.; Moura, F.C.C.; Hernández-Terrones, M.G.; Lago, F.M.P.M. Amphiphilic magnetic composites based on layered vermiculite and fibrous chrysotile with carbon nanostructures: Application in catalysis. Catal. Today 2012, in press.

11. Teixeira, A.P.D.C.; Lemos, B.R.S.; Magalhães, L.A.; Ardisson, J.D.; Lago, R.M.; Furtado, C.A.; Santos, A.P. Temperature programmed CVD: A novel technique to investigate carbon nanotube synthesis on FeMo/MgO Catalysts. J. Nanosci. Nanotechnol. 2012, 12, 2661-2667.

12. Purceno, A.D.; Teixeira, A.P.C.; Souza, N.J.d.; Fernandez-Outon, L.E.; Ardisson, J.D.; Lago, R.M. Hybrid magnetic amphiphilic composites based on carbon nanotube/nanofibers and vermiculite as efficient adsorbent for ethynilestradiol. J. Colloid Interface Sci. 2012, in press.

13. Purceno, A.D.; Barrioni, B.R.; Dias, A.; da Costa, G.M.; Lago, R.M.; Moura, F.C.C. Carbon nanostructures-modified expanded vermiculites produced by chemical vapor deposition from ethanol. Appl. Clay Sci. 2011, 54, 15-19.

14. Thompson, S.K.; Mason, E. Asbestos: Mineral and fibers. J. Chem. Health Saf. 2002, 21-23.

15. Morgan, A. Acid leaching studies of chrysotile asbestos from mines in the Coalinga region of California and from Quebec and British Columbia. Ann. Occup. Hyg. 1997, 41, 249-265.

16. Boni, L.d.; Goldani, E.; Milcharek, C.; Santos, F. Tratamento físico-químico da água de lavagem proveniente da purificação do biodiesel. Tche-química 2007, 7, 41-50.

17. Trigueiro, J.P.C.; Silva, G.G.; Lavall, R.L.; Furtado, C.A.; Oliveira, S.; Ferlauto, A.S.; Lacerda, R.G.; Ladeira, L.O.; Liu, J.W.; Frost, R.L.; George, G.A. Purity evaluation of carbon nanotube materials by thermogravi metric, TEM, and SEM methods. J. Nanosci. Nanotechnol. 2007, 7, 3477-3486.

18. Dresselhaus, M.S.; Dresselhaus, G.; Saito, R.; Jorio, A. Raman spectroscopy of carbon nanotubes. Phys. Rep.-Rev. Sect. Phys. Lett. 2005, 409, 47-99.

19. Jorio, A.; Pimenta, M.A.; Souza, A.G.; Saito, R.; Dresselhaus, G.; Dresselhaus, M.S. Characterizing carbon nanotube samples with resonance Raman scattering. New J. Phys. 2003, 5, 139:1-139:17. 
20. Cattaneo, A.; Gualtieri, A.F.; Artioli, G. Kinetic study of the dehydroxylation of chrysotile asbestos with temperature by in situ XRPD. Phys. Chem. Miner. 2003, 30, 177-183.

21. Sarvaramini, A.; Larachi, F. Mössbauer Spectroscopy and Catalytic Reaction Studies of Chrysotile-Catalyzed Steam Reforming of Benzene. J. Phys. Chem. C 2011, 115, 6841-6848.

22. Ristic, M.; Czako-Nagy, I.; Music, S.; Vertes, A. Spectroscopic characterization of chrysotile asbestos from different regions. J. Mol. Struct. 2011, 993, 120-126.

23. Eisenbach, M.; Nicholson, D.M.; Rusanu, A.; Brown, G. First principles calculation of finite temperature magnetism in $\mathrm{Fe}$ and $\mathrm{Fe}_{3}$ C. J. Appl. Phys. 2011, 109, 07E138:1-07E138:2.

(C) 2012 by the authors; licensee MDPI, Basel, Switzerland. This article is an open access article distributed under the terms and conditions of the Creative Commons Attribution license (http://creativecommons.org/licenses/by/3.0/). 